\title{
Muito para além da encefalite: um relato de caso
}

Ana Rita Martins dos Reis*

\section{RESUMO}

Introdução: O estado confusional agudo traduz uma alteração súbita do estado de consciência. A sua etiologia é geralmente multifatorial e mais difícil de determinar nos idosos. Pode estar associado a múltiplas patologias, com diferente gravidade, orientação e prognóstico. Este caso clínico ilustra uma apresentação incomum de um tumor cerebral, mostra como o médico de família foi um apoio importante do utente e da família e como a continuidade de cuidados é fundamental na medicina geral e familiar.

Descrição do caso: Homem de 69 anos, casado, autónomo. Tem história de diabetes mellitus tipo 2 com complicações, hipertensão arterial, múltiplas comorbilidades cardiovasculares e obesidade. Foi trazido à consulta por alterações súbitas de comportamento e confusão mental, sem febre. Foi orientado para o serviço de urgência, apresentando-se então febril e sendo diagnosticada encefalite vírica. Após internamento prolongado regressou ao domicílio, parcialmente dependente. A recuperação foi mais lenta que o expectável e o acompanhamento clínico revelou um tumor cerebral com prognóstico reservado. As dificuldades de adaptação da família ao diagnóstico e à dependência foram evidentes, o que se traduziu em múltiplas visitas ao serviço de urgência e várias complicações. Faleceu nove meses depois.

Comentários: Uma doença súbita, particularmente quando altera o grau de dependência, exige adaptação de toda a família. O médico de família foi um elemento importante na gestão da situação: orientou, na incerteza, o problema inicial, apoiou na recuperação da doença aguda, informou, educou, disponibilizou-se, aproximou-se, cuidou do utente e deu apoio ao cuidador. Contudo, a expectativa de recuperação dificultou a comunicação e a relação terapêutica entre a equipa de saúde e a família. Considera-se que este caso, mesmo refletindo todas as competências do médico de família, evidencia como os medos e as expectativas podem condicionar o resultado final na prestação de cuidados.

Palavras-chave: Estado confusional agudo; Encefalite; Glioblastoma; Expectativas.

\section{INTRODUÇÃO}

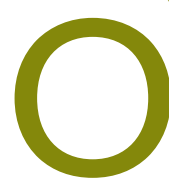

estado confusional agudo (ECA) corresponde a uma alteração súbita do conteúdo da consciência. Caracteriza-se por uma combinação variável de diminuição da atenção, discurso incoerente, desorientação no tempo e no espaço, agitação psicomotora ou sonolência, alucinações e alteração do ciclo de sono-vigília. ${ }^{1}$

Ocorre em até $50 \%$ dos idosos internados em hospital, até $80 \%$ dos idosos admitidos em unidades de cuidados intensivos e em 1 a $2 \%$ da população em geral.

A sua etiologia pode ser única ou multifatorial.Dentro das causas mais comuns encontramos causas metabólicas (hipóxia, hipoglicémia, hiperglicémia, hipertiroidismo, desequilíbrios hidroeletrolíticos, desidratação, exposição a álcool, intoxicação por monóxido de

* Médica Interna de Medicina Geral e Familiar USF Terras de Santa Maria, ACeS Entre Douro e Vouga I (Feira/Arouca) carbono, entre outras), infeções (pneumonia, infeção urinária, endocardite, meningite, encefalite, abcesso cerebral, sépsis, entre outras), causas vasculares (enfarte agudo do miocárdio, tromboembolismo pulmonar, hemorragias intracranianas, encefalopatia hipertensiva, isquémia cerebral talâmica, entre outros), epilepsia e fármacos. Estas deverão ser as primeiras causas a excluir perante um doente com ECA. ${ }^{1}$

Assim, constata-se que o diagnóstico diferencial perante um doente com ECA pode ser um enorme desafio, particularmente se se trata de um idoso. Contudo, dada a elevada probabilidade de se tratar de uma situação potencialmente ameaçadora da vida, todos os doentes devem ser investigados. ${ }^{1}$

Este caso clínico ilustra uma apresentação incomum de um tumor cerebral e o percurso pelos diagnósticos atribuídos ao utente ao longo do tempo. Além disso, as autoras consideram-no um bom exemplo para reflexão acerca das competências específicas do médico de 
família. Neste caso foi este o principal apoio do utente e o "continente das angústias" da família, aquele com quem partilharam os seus medos, receios e esperanças em todas as fases da doença, mostrando como a continuidade de cuidados é fundamental em medicina geral e familiar ${ }^{2}$ e como as expectativas de cada elemento podem condicionar a prestação de cuidados.

\section{DESCRIÇÃO DO CASO}

\section{Identificação e história pessoal}

Homem de 69 anos de idade, de raça caucasiana, natural de Arouca, residente em Santa Maria da Feira e sem história recente de viagens. Tem uma escolaridade de quatro anos, está reformado e trabalhou nas áreas de comércio e restauração.

Trata-se de um utente com múltiplas patologias e comorbilidades. Apresenta diabetes mellitus de tipo 2 com vinte e quatro anos de evolução, com controlo metabólico razoável (última hemoglobina glicada de 7,4\%), neuropatia periférica e doença vascular periférica com catorze anos de evolução e nefropatia diabética diagnosticada há dez anos, com doença renal crónica de grau 2 (última microalbuminúria de $250 \mathrm{mg} / 24 \mathrm{~h}$ e última taxa de filtração glomerular estimada de $76 \mathrm{~mL} / \mathrm{min} / 1,73 \mathrm{~m}^{2}$ ). Tem hipertensão arterial (HTA) essencial desde há catorze anos, obesidade (índice de massa corporal de 30,8 $\mathrm{Kg} / \mathrm{m}^{2}$ ), doença cardíaca isquémica com angina, história de dois enfartes agudos do miocárdio (doze e três anos atrás), com necessidade de cirurgia de bypass coronário em 2011 por doença aterosclerótica coronária de três vasos, síndroma de apneia obstrutiva do sono, sob ventiloterapia noturna (oito horas) e perturbação ansiosa.

É um ex-fumador desde 2011 (com uma carga tabágica de 36 unidades maço-ano), com um consumo médio de 96 g de álcool por semana, sem outros consumos toxicológicos conhecidos. Tem um estilo de vida sedentário.

O seu Plano Nacional de Vacinação está atualizado, tem a vacina da gripe sazonal atualizada em 2014 e a vacina antipneumocócica em 2012. Desconhece alergias medicamentosas ou alimentares.

A sua medicação habitual inclui: omeprazol $20 \mathrm{mg}$ q.d., furosemida $40 \mathrm{mg}$ q.d., candesartan $16 \mathrm{mg}$ q.d., amlodipina 10mg q.d., atenolol 50mg q.d., pravastatina $20 \mathrm{mg}$ q.d., pentoxifilina $400 \mathrm{mg}$ tid, mononitrato de isossorbido 50mg q.d., ácido acetilsalicílico 100mg q.d., metformina 1000mg tid, insulina glargina $10 \mathrm{U}$ antes de deitar e insulina de mistura (30\% insulina aspártico + $70 \%$ insulina aspártico protaminada), de acordo com as medições de glicémia capilar.

\section{Caracterização familiar}

O utente integra uma família nuclear, em fase VIII do ciclo familiar de Duvall e de classe socioeconómica III (média), segundo a escala de Graffar.

É casado há 44 anos, tem dois filhos e três netos. $\mathrm{O}$ filho mais velho do casal é casado e reside no Brasil com a esposa e com os três filhos. O filho mais novo regressou a Portugal após o divórcio, estando atualmente a viver com os pais.

Apresenta-se o genograma desta família e o respetivo agregado familiar (Figura 1), segundo informações da esposa do utente. Não está representada a psicofigura de Mitchell por não ter sido possível recolher essa informação junto do utente.

\section{História da doença atual}

\section{Consulta não programada (11/02/2014)}

$\mathrm{O}$ utente foi trazido à consulta aberta pela esposa $\mathrm{e}$ pelo filho porque, de forma súbita e desde o dia anterior, apresentava alterações de comportamento. A esposa referia que "o meu marido está estranho" (sic). Notavam que interagia menos que o habitual, apresentava desequilíbrio na marcha, rodava sobre ele próprio, parecia ter alucinações visuais ["vê televisão na parede" (sic)]. Não notaram outras queixas, nomeadamente dores ou febre até ao momento. Referiram que tinha deixado de utilizar o dispositivo de CPAP (Continuous Positive Airway Pressure) duas semanas antes por intolerância à máscara, depois do aparecimento de lesão cutânea junto ao nariz. Ao exame objetivo apresentava-se confuso, pouco colaborante, estava orientado autopsiquicamente, mas desorientado no espaço. O estado de consciência parecia ter ligeiras flutuações. O seu discurso era incoerente e apenas era capaz de responder corretamente a ordens simples. Não parecia reter a informação fornecida, com aparente défice de memória de curto prazo. Apresentava uma postura inquieta e comportamentos repetidos: movimentos estereotipados das mãos, rodava sobre o próprio eixo quando tentava iniciar a marcha. Pediu várias vezes água na consulta. Quando questionado sobre as suas queixas não foi capaz de as explicar, negando sintomas como dispneia, cefaleias ou outras queixas ál- 


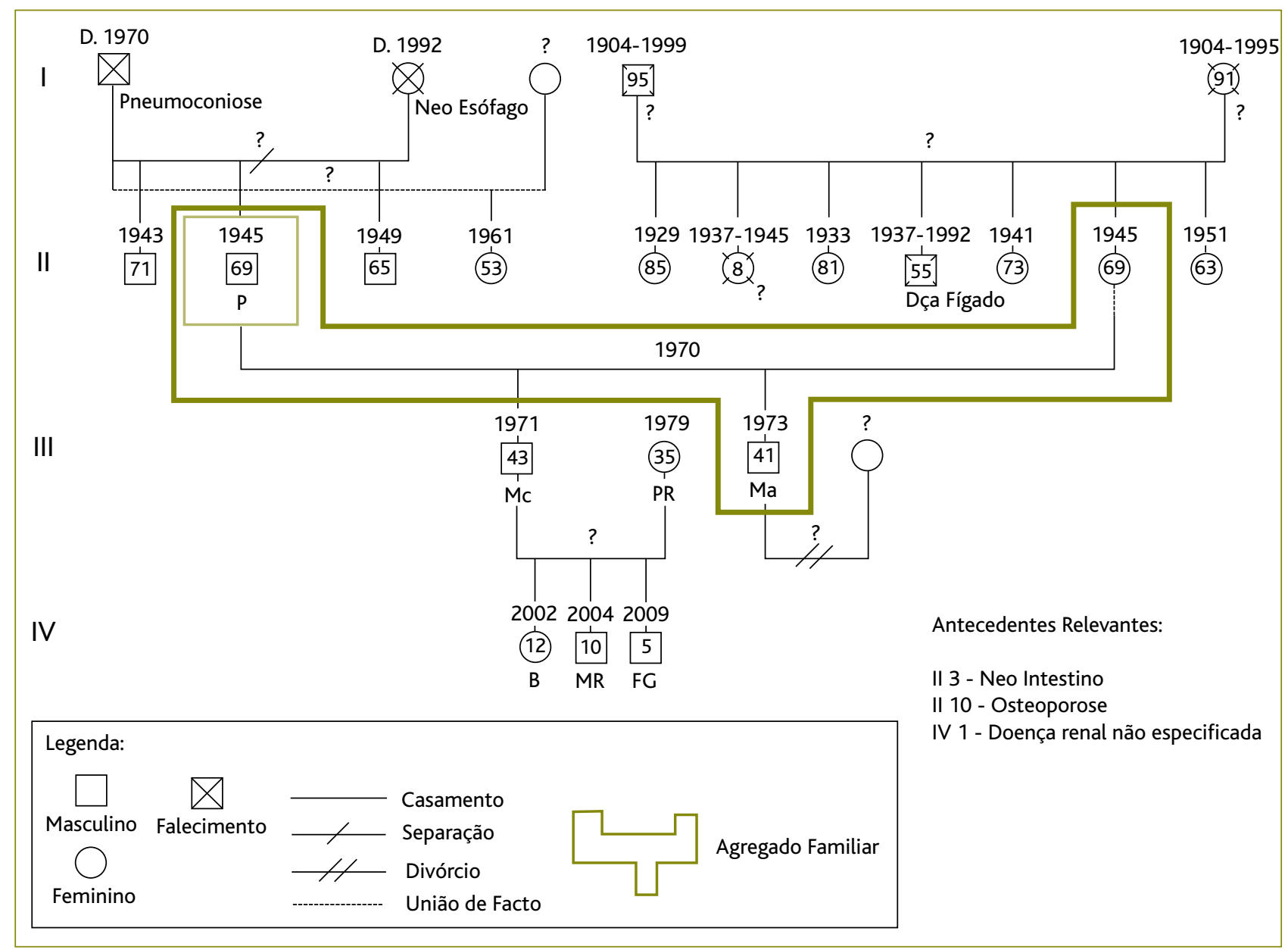

Figura 1. Genograma familiar (março de 2014).

gicas. A sua pressão arterial era de $213 / 98 \mathrm{mmHg}$, a auscultação cardiopulmonar não tinha alterações e a glicémia capilar era de $330 \mathrm{mg} / \mathrm{dL}$. Observavam-se várias lesões vesiculares junto à asa direita do nariz, sugestivas de Herpes simplex. Quanto ao exame neurológico sumário, os pares cranianos não apresentavam alterações, não se objetivaram défices de força muscular, as provas de coordenação foram difíceis de avaliar por menor colaboração do utente e a prova de Romberg era duvidosa para a direita. Notamos que a sua capacidade de atenção para as tarefas foi diminuindo ao longo da consulta. Não foram testadas as sensibilidades nem os reflexos osteotendinosos. Os sinais meníngeos foram difíceis de avaliar, mas eram aparentemente negativos. Observamos uma marcha de base ligeiramente alargada, mas não foram realizadas outras provas.
Perante o quadro de estado confusional agudo do utente, consideraram-se algumas hipóteses de diagnóstico mais prováveis: descompensação metabólica da diabetes mellitus, dado que apresentava sede, confusão mental e elevação da glicémia capilar; hipóxia cerebral de etiologia multifatorial, dado que se trata de um doente com elevado risco cardiovascular, com HTA descontrolada e com história recente de suspensão de CPAP. Considerou-se a possibilidade de evento vascular cerebral agudo, secundário à HTA e com possível influência da suspensão do CPAP no agravamento do risco cardiovascular global. Afigurou-se-nos menos provável que a suspensão da ventiloterapia fosse causa de uma hipóxia cerebral instalada de forma mais lenta e progressiva. Considerou-se também a hipótese de lesão do sistema nervoso central (SNC), infeção ou lesão 
tumoral, dada a sintomatologia e as alterações neurológicas que apresentava, embora não apresentasse febre no momento da observação e o aparecimento súbito fosse pouco a favor de uma lesão ocupante de espaço. Considerámos ainda a possibilidade de demência rapidamente progressiva por se apresentar desorientado no tempo, com discurso incoerente e com défices mnésicos, embora a instalação tão súbita e os achados do exame neurológico não fossem favoráveis.

Assim, o utente foi referenciado ao serviço de urgência (SU) do hospital de referência para ser avaliado.

\section{Serviço de urgência (11/02/2014)}

Algumas horas depois foi observado no SU do hospital de referência, tendo sido solicitada avaliação por neurologista. A sua observação foi sobreponível à realizada na Unidade de Saúde Familiar (USF), mas o utente apresentava-se febril $\left(39,8^{\circ} \mathrm{C}\right)$ e com alguns períodos de agitação psicomotora, pelo que a hipótese de infeção se tornou a mais provável. Assim, foi realizada punção lombar e o utente ficou internado com o diagnóstico provável de encefalite vírica, possivelmente herpética. Iniciou tratamento empírico com aciclovir endovenoso.

\section{Internamento (11/02/2014 - 27/03/2014)}

O estado do utente melhorou nos primeiros dias de internamento, apresentando-se progressivamente menos confuso e mais orientado. A punção lombar revelou pleocitose, com predomínio polimorfonuclear (92\%) e não foi identificado nenhum agente microbiano. No terceiro dia de internamento realizou ressonância magnética cerebral, que se revelou compatível com o diagnóstico inicial de encefalite.

Contudo, surgiram algumas complicações médicas que prolongaram o internamento, nomeadamente a ocorrência de lesão renal aguda por provável toxicidade ao aciclovir e uma infeção nosocomial por Staphylococcus aureus no contexto da presença de cateter venoso central.

A estabilização destes problemas de saúde demorou cerca de um mês e meio, em que o utente esteve confinado ao leito, pelo que o seu estado de dependência se alterou. À data da alta apresentava dependência parcial nas atividades de vida diárias, tendo sido encaminhado para consultas de medicina física e de reabilitação (MFR). Manteve acompanhamento em consulta externa de neurologia.

\section{Consulta ao domicílio (09/04/2014)}

Esta consulta foi agendada pela médica de família, com o intuito de reavaliar o utente após o internamento prolongado. A esposa referiu que tinha recuperado a autonomia para a maioria das atividades de vida diárias (vestir, comer e higiene pessoal), necessitando de ajuda para o banho e algum auxílio na marcha, pelo desequilíbrio. Ao exame objetivo apresentava-se calmo, com aspeto descuidado, emagrecido, consciente e colaborante, com alguns períodos de discurso incoerente. Deambulava sem apoio de auxiliares, mas com marcha cautelosa, de base alargada, apoiada nas paredes $\mathrm{e}$ móveis. Estava normotenso, apirético e sem alterações da auscultação cardiopulmonar. Os seus registos de glicémia capilar variavam entre $95 \mathrm{mg} / \mathrm{dL}$ e $243 \mathrm{mg} / \mathrm{dL}$ (o utente apenas fazia avaliação em jejum). Mantinhamse as dificuldades de memória de curto prazo.

Tendo em conta a natureza da infeção e as complicações do internamento, interpretou-se esta evolução como uma recuperação mais lenta do quadro de encefalite. Em doentes mais jovens, a sintomatologia pode reverter em alguns dias e podem não surgir sequelas. No caso dos doentes mais idosos, a recuperação pode demorar algumas semanas ${ }^{3}$ e, neste caso, foi explicada à família a possibilidade de existirem sequelas e o utente ficar com algumas limitações, nomeadamente de equilíbrio e de memória.

\section{Evolução}

Em 09/06/2014, o utente recorreu com a esposa à USF para consulta de vigilância da diabetes mellitus. Apresentava melhoria global do seu estado geral, marcha autónoma e sem apoio e independência nas atividades de vida diárias. Porém, no mês seguinte foi novamente levado ao SU do hospital de referência por agravamento das dificuldades na marcha, novos períodos de confusão mental e episódios de incontinência urinária. A revisão dos exames complementares de diagnóstico pela equipa de neurologia, que reobservou o utente, fez surgir a dúvida quanto ao diagnóstico inicial, uma vez que o agravamento não era expectável, pelo que foi repetida a ressonância magnética cerebral. Esta revelou uma "extensa lesão hemisférica direita, com invasão do corpo caloso, compatível com glioblastoma multiforme (...)". Foi encaminhado para consulta de neurocirurgia urgente que considerou, dada a extensão da lesão, tra- 
tar-se de uma situação inoperável, com prognóstico reservado e não sendo de prever tratamentos complementares e apenas medidas de conforto.

\section{Consulta ao domicílio (03/09/2014)}

Esta consulta foi solicitada pela esposa, na sequência do agravamento global do estado de saúde do utente e do novo diagnóstico. Este encontrava-se deitado na cama, sonolento, confuso e desorientado. A interação era escassa e difícil. Estava pálido e emagrecido. Apresentava um índice de Barthel com dependência grave. A preocupação principal da equipa de saúde foi compreender como a esposa reagira ao novo diagnóstico e como estava a adaptar-se à sua nova condição de cuidadora de uma pessoa dependente. Foram recomendadas algumas ajudas técnicas (colchão de pressão alternada) e foi fornecida informação escrita sobre os cuidados a doentes dependentes, bem como instituições de apoio domiciliário a que poderia recorrer.

A figura seguinte (Figura 2) resume os principais acontecimentos relatados.

\section{Evolução}

Nos meses que se seguiram foram evidentes as dificuldades de adaptação deste agregado familiar e particularmente da esposa do utente. Esta manteve-se sempre muito renitente em aceitar o prognóstico reservado inerente ao diagnóstico de um tumor cerebral agressivo, permanecendo com uma atitude de esperança de recuperação, o que dificultou significativamente a comunicação e a relação terapêutica. O filho alienou-se da situação, não se conseguindo o seu envolvimento nos cuidados ao pai. A médica e a enfermeira de família disponibilizaram-se para acompanhar o utente no domicílio sempre que fosse necessário, procuraram em vários momentos informar a esposa do utente sobre o prognóstico, esclarecer todas as dúvidas, informar sobre que cuidados seriam previsivelmente necessários e quais os recursos disponíveis a que poderiam recorrer, nomeadamente apoio domiciliário e programas de apoio ao cuidador. Este acompanhamento foi fundamental, uma vez que da parte do hospital, depois de dado o diagnóstico e estabelecido o prognóstico, não foi estabelecido qualquer plano de cuidados.

Por várias vezes foram recusadas as ajudas técnicas que iam sendo conseguidas, como a cama articulada ou o colchão de pressão alternada. Aceitaram, com alguma reserva e por um curto período de tempo, a recomendação de apoio domiciliário para a higiene e alimentação. A comunicação passou a ser difícil, dado que as preocupações da esposa se centravam apenas nos medicamentos, não escutando as recomendações em relação aos posicionamentos, a prevenção de úlceras de pressão, cuidados com a alimentação, entre outros. Os contactos presenciais da enfermeira de família passaram a ser mais regulares e foram complementados com contactos telefónicos semanais no sentido de esclarecer dúvidas sobre os cuidados a prestar, interação com a equipa de apoio domiciliário e acompanha-

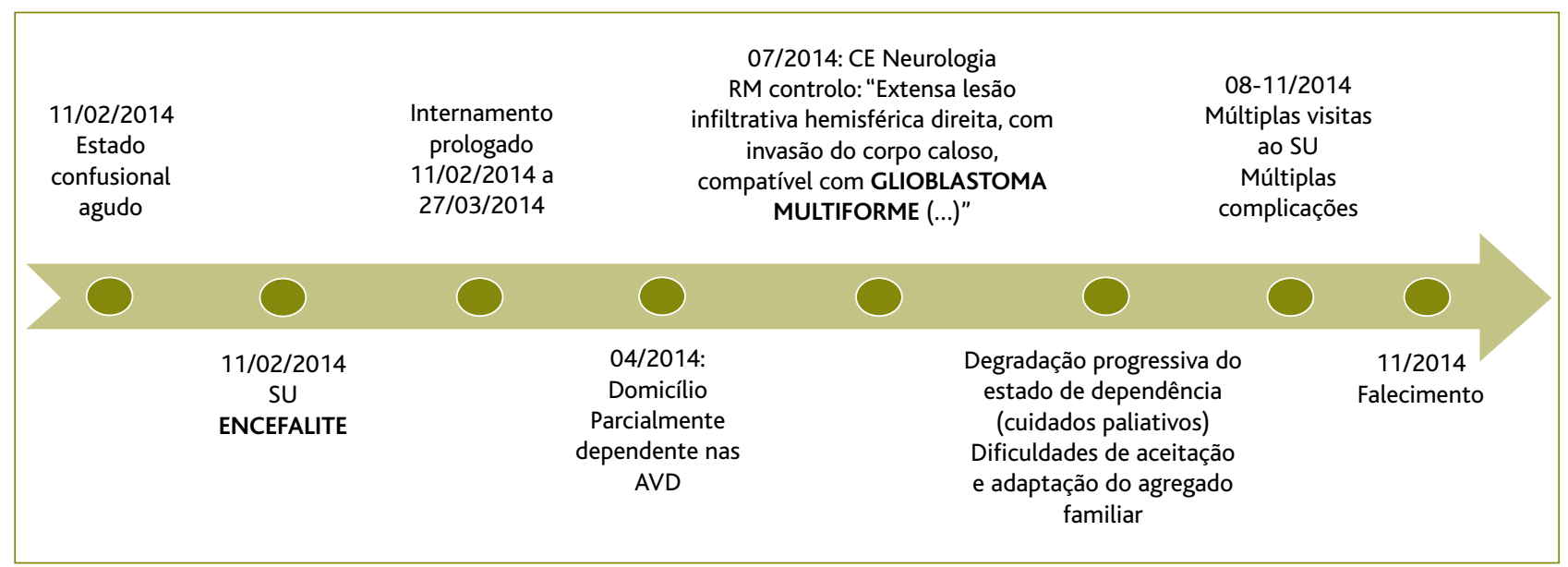

Figura 2. Resumo dos principais acontecimentos da história clínica.

Legenda: SU - serviço de urgência; AVD - atividades de vida diárias; CE - consulta externa; RM - ressonância magnética 
mento da esposa enquanto cuidadora informal. A médica de família passou a visitar o utente no domicílio mensalmente, para acompanhamento do plano de cuidados e para prestar apoio à esposa, que sempre recusou participar no programa de apoio ao cuidador existente na comunidade. Foi oferecida a possibilidade de ingresso do utente na Rede Nacional de Cuidados Continuados Integrados, que a família aceitou (e que o utente não chegou a utilizar).

O estado de saúde do utente foi-se degradando, apresentando-se emagrecido, apático, confuso e desorientado, quase sem interação com o meio envolvente e praticamente confinado ao leito. Surgiram várias úlceras de pressão, tratadas pela enfermeira de família, que passou a visitar o doente no domicílio várias vezes por semana.

Sucederam-se várias visitas ao SU do hospital de referência, por múltiplas complicações médicas que foram surgindo (pneumonia, tromboembolismo pulmonar, agitação psicomotora). A última visita, em novembro de 2014, conduziu a internamento por infeção respiratória e culminou com o falecimento do utente.

\section{COMENTÁRIO}

O ECA pode constituir um enorme desafio clínico, particularmente quando se trata de um idoso. Pode ser causado por inúmeras situações e muitas delas apresentam-se com sinais e sintomas clínicos inespecíficos. Assim, é importante que haja elevado grau de suspeição para este diagnóstico diferencial, uma vez que algumas situações podem ser graves e/ ou colocar a vida do doente em risco. ${ }^{1}$

A encefalite apresentou-se, neste caso, como um primeiro diagnóstico. Esta infeção do SNC apresenta-se mais frequentemente nos extremos de idade, ou seja, crianças e idosos. A etiologia vírica é a mais frequente e, quando o tratamento é instituído precocemente, as possibilidades de recuperação sem sequelas são significativas. Contudo, nos idosos (e particularmente naqueles com comorbilidades) os casos podem ser mais graves e a recuperação pode ser mais lenta a gradual. ${ }^{3}$ Neste caso em particular, a evolução não foi de acordo com o expectável, nem para a família nem para os médicos, alterando a situação deste agregado familiar. A esposa passou a desempenhar, subitamente, o papel de cuidadora, tendo experienciado várias dificuldades na adaptação a um doente dependente. Começou a de- monstrar sinais de insegurança na prestação de cuidados, medo, depressão e exaustão.

A evolução desfavorável e o progressivo agravamento do estado clínico do utente conduziu a que, numa ida ao SU, fosse reavaliado pela equipa de neurologia. Assim, apresentou-se um novo diagnóstico, que trouxe consigo uma realidade ainda mais negativa: um tumor cerebral, avançado, inoperável e com prognóstico reservado.

Não se trata de um caso inédito de um tumor cerebral que se apresenta inicialmente como uma encefalite. Existem alguns casos relatados na literatura a esse respeito, ${ }^{4-5}$ incluindo um em Portugal. ${ }^{6}$ Embora seja uma situação rara, o diagnóstico de tumor cerebral deverá ser considerado em doentes cujo quadro inicial de encefalite difira muito daquilo que é o curso esperado. Geralmente são tumores com elevado grau de malignidade e que, mesmo com o tratamento adequado, têm uma sobrevida baixa e elevadas taxas de recorrência. ${ }^{3}$ Assim, os cuidados paliativos tornam-se fundamentais. Não existindo uma equipa específica disponível para a prestação desses cuidados, foi à médica e à enfermeira de família que coube esse papel. Para além do ajuste terapêutico farmacológico à nova condição do utente, a médica de família procurou assegurar que se informava e esclarecia a família sobre os potenciais sintomas que poderiam surgir e o que poderia ser feito pelos familiares em cada uma das situações, nomeadamente agitação psicomotora, insónia ou queixas álgicas. Assegurou também o ensino de atuação não farmacológica e farmacológica no caso de surgirem convulsões. A enfermeira de família teve um papel muito relevante na educação sobre posicionamentos no leito, cuidados com a alimentação e cuidados de enfermagem nas úlceras de pressão. Toda a equipa de saúde procurou colaborar na psicoeducação e na prevenção de depressão e exaustão da esposa, enquanto cuidadora.

Assim, a equipa de saúde colocou especial esforço e empenho no acompanhamento deste utente e desta família. Porém, cedo se deparou com variadas dificuldades na comunicação e na relação terapêutica. A esposa manteve esperança na recuperação, o que constituiu uma enorme barreira à prestação de cuidados de conforto ao utente, uma vez que várias ajudas técnicas (cama articulada e colchão de pressão alternada) e apoios (apoio domiciliário na higiene e alimentação) foram recusados por considerar não serem necessá- 
rios. A comunicação tornou-se difícil, não por conflito, mas pelas diferentes expectativas e a insegurança em cuidar traduziu-se em inúmeras visitas ao SU no fim de vida do utente. Pareceu à equipa de saúde que o recurso ao hospital por parte da família era mais uma manifestação desta esperança na recuperação, não estando, nem esposa nem filho, preparados para aceitar a prestação de cuidados de fim de vida no domicílio.

Continuamos a acompanhar esta esposa no luto e a trabalhar na comunicação e na construção de uma relação terapêutica sólida e de confiança.

Consideramos este caso como um exemplo rico daquilo que são as competências do médico de família. Além da capacidade de diagnóstico e de orientação terapêutica, o médico de família tem uma relação de proximidade privilegiada a todos os níveis, o que pode ser um facilitador nos cuidados continuados e globais ao utente, mas que se revelou, nesta situação, frustrante para a equipa de saúde, uma vez que o seu propósito na prestação de cuidados era diferente do da família: cuidados de conforto no domicílio em fim de vida. Apesar de todos os esforços, disponibilidade e tentativas, não foi possível chegar a esse ponto de sintonia e a equipa de saúde cumprir o seu objetivo.

\section{REFERÊNCIAS BIBLIOGRÁFICAS}

1. García-Antelo MJ. Síndrome confusional agudo. Cad Aten Primaria. 2012;18(4):303-5.

2. Morgan ED, Pasquarella M, Holman JR. Continuity of care and patient satisfaction in a family practice clinic. J Am Board Fam Pract. 2004;17(5): 341-6.

3. Sá MJ. Neurologia clínica: compreender as doenças neurológicas. Porto: Edições Universidade Fernando Pessoa; 2009. ISBN 9789896430344

4. Nam TS, Choi KH, Kim MK, Cho KH. Glioblastoma mimicking herpes simplex encephalitis. J Korean Neurosurg Soc. 2011;50(2):119-22.

5. Nagata R, Ikeda K, Nakamura Y, Ishikawa Y, Miura K, Sato R, et al. A case of gliomatosis cerebri mimicking limbic encephalitis: malignant transformation to glioblastoma. Intern Med. 2010;49(13):1307-10.

6. Nunes J, Carvalho S, Gouveia P, Shamasna M, Costa B, Alves JL, et al. Glioblastoma multiforme mimetizando encefalite límbica [Glioblastoma multiforme mimicking limbic encephalitis]. Acta Med Port. 2012;25 Suppl 1:48-51. Portuguese

\section{CONFLITOS DE INTERESSE}

A autora declara não ter conflitos de interesse.

\section{ENDEREÇO PARA CORRESPONDÊNCIA}

Ana Rita Martins dos Reis

E-mail: aritamreis@gmail.com

Recebido em 24-03-2016

Aceite para publicação em 13-02-2017

\section{ABSTRACT}

\section{BEYOND ENCEPHALITIS: A CASE REPORT}

Introduction: An acute confusional state reflects a sudden change in consciousness. The etiology is usually multifactorial and the diagnosis is more difficult in the elderly. It may be associated with many diseases, each with a different severity, management and prognosis. This case illustrates a rare presentation of a brain tumor as a confusional state. It demonstrates the role of the family physician as the main support for the patient and the family and the importance of continuity of care.

Case report: A 69 year-old married man was brought to a consultation because of sudden behavioral changes and mental confusion, without fever. He was known to suffer from type 2 diabetes, arterial hypertension, cardiovascular disease, and obesity. He was referred to the emergency room, where he became febrile. Viral encephalitis was diagnosed. After a prolonged hospitalization, he returned home and became partially dependent. His recovery was slower than expected. A follow-up examination revealed a glioblastoma multiforme. The family had difficulty adjusting to the diagnosis and the dependent state of the patient. There were many visits to the emergency department and multiple complications. He died nine months later.

Comments: Sudden illness, particularly when it changes the degree of dependence of the patient, requires adaptation by the family. The family physician had an important role to play in the management of this situation. He managed the initial presentation, provided support in the recovery from the acute illness, informed and educated and the patient and the family, made himself available to the family, cared for the patient, and supported the caregivers. However, the expectations of the family for a full recovery hindered communication between the health care team and the family. In this case, despite expert care by the physician, the fears and expectations of the patient and family can jeopardize a desired outcome.

Keywords: Acute confusional state; Encephalitis; Glioblastoma; Expectations. 